\title{
Erratum to: Micropapillary and/or Solid Histologic Subtype Based on Pre-Treatment Biopsy Predicts Local Recurrence After Thermal Ablation of Lung Adenocarcinoma
}

\author{
Song Gao ${ }^{1,2} \cdot$ Seth Stein $^{1} \cdot$ Elena N. Petre $^{1} \cdot$ Waleed Shady $^{1} \cdot$ Jeremy C. Durack $^{1}$ • \\ Carole Ridge $^{1,3} \cdot$ Prasad S. Adusumilli $^{4} \cdot$ Natasha Rekhtman $^{5} \cdot$ Stephen B. Solomon $^{1}$. \\ Etay Ziv ${ }^{1}$ (D)
}

Published online: 10 August 2017

(C) Springer Science+Business Media, LLC and the Cardiovascular and Interventional Radiological Society of Europe (CIRSE) 2017

\section{Erratum to: Cardiovasc Intervent Radiol DOI 10.1007/s00270-017-1760-8}

In the published article, the middle initial "S." is missing from the author name "Prasad Adusumilli". The author's complete name as listed in this erratum is "Prasad S. Adusumilli”.

The online version of the original article can be found under doi:10.1007/s00270-017-1760-8.

Etay Ziv

zive@mskcc.org

1 Interventional Radiology Service, Memorial Sloan-Kettering Cancer Center, Howard-118, 1275 York Ave, New York, NY 10065, USA

2 Interventional Therapy Department, Key Laboratory of Carcinogenesis and Translational Research (Ministry of Education Beijing), Peking University Cancer Hospital and Institute, Beijing 100142, China

3 Department of Radiology, Mater Misericordiae, University Hospital, Dublin 7, Ireland

4 Thoracic Surgery Service, Memorial Sloan-Kettering Cancer Center, Howard-118, 1275 York Ave, New York, NY 10065, USA

5 Pathology Diagnostic Service, Memorial Sloan-Kettering Cancer Center, Howard-118, 1275 York Ave, New York, NY 10065, USA 